\title{
Is utility-based quality of life associated with overweight in children? Evidence from the UK WAVES randomised controlled study
}

Emma J. Frew ${ }^{1 *}$, Miranda Pallan², Emma Lancashire ${ }^{2}$, Karla Hemming ${ }^{2}$, Peymane Adab ${ }^{2}$ and on behalf of the WAVES Study co-investigators

\begin{abstract}
Background: Quality-Adjusted Life Years (QALYS) are often used to make judgements about the relative costeffectiveness of competing interventions and require an understanding of the relationship between health and health-related quality of life (HRQOL) when measured in utility terms. There is a dearth of information in the literature concerning how childhood overweight is associated with quality of life when this is measured using utilities. This study explores how weight is associated with utility-based HRQOL in 5-6 year olds and examines the psychometric properties of a newly developed pediatric utility measure - the CHU9D instrument.

Methods: Weight and HRQOL were examined using data collected from 1334 children recruited within a UK randomised controlled trial (WAVES) (ISRCTN97000586). Utility-based HRQOL was measured using the CHU9D, and general HRQOL measured using the PedsQL instrument. The association between weight and HRQOL was examined through a series of descriptive and multivariate analysis. The construct validity of the CHU9D was further assessed in relation to weight status, in direct comparison to the PedsQL instrument.

Results: The HRQOL of children who were either overweight or obese was not statistically different from children who were healthy or underweight. This result was the same for when HRQOL was measured in utility terms using the CHU9D instrument, and in general terms using the PedsQL instrument. Furthermore, the results support the construct validity of the newly developed CHU9D as the PedsQL total HRQOL scores corresponded well with the individual CHU9D dimensions.

Conclusion: At age 5-6 years, the inverse association between overweight and HRQOL is not being captured by either the utility-based CHU9D instrument nor the PedsQL instrument. This result has implications for how the cost-effectiveness of childhood obesity interventions is measured in children aged 5-6 years.
\end{abstract}

Trial registration: ISRCTN Registry: ISRCTN97000586 $19^{\text {th }}$ May 2010.

Keywords: Health-related quality of life, Utility, CHU9D, BMI, Children, UK

\section{Background}

Childhood obesity is a growing problem worldwide [1-3]. The direct annual costs of obesity and associated health consequences across the $\mathrm{EU}$ is about $7 \%$ of national health budgets [4] and within the UK National Health Service (NHS), is approximately $£ 4.2$ billion, with an estimated cost of $£ 16$ billion to the wider economy [5].

\footnotetext{
* Correspondence: e.frew@bham.ac.uk

'Health Economics Unit, University of Birmingham, Birmingham B15 2T, UK Full list of author information is available at the end of the article
}

A range of interventions have been developed to prevent and manage childhood obesity [6]. However, there is an absence of evidence on the costeffectiveness of such interventions. Whilst there is much evidence to suggest that weight status has an effect on adult health-related quality of life (HRQOL) [7-11], and many studies have reported similar associations in adolescents [12-14], these studies report HRQOL in general terms rather than in the more 
specific utility terms required for an economic analysis. In the UK, for decision making bodies such as the National Institute for Health and Care Excellence (NICE) it is recommended that HRQOL is measured in utility terms to facilitate the construction of Quality-Adjusted Life Years (QALYs). QALYs are then used as the unit of assessment for comparing the cost-effectiveness of alternative interventions [15] and are now used to inform resource allocation decisions worldwide [16]. Conventional practice within economic evaluations is to measure HRQOL on a cardinal $0-1$ utility scale with death $(0)$ and full health (1) denoting either end of the scale [17]. Very few studies have looked at the impact of childhood overweight/obesity on HRQOL when it is measured in utility terms [18] yet this information is vital for the construction of QALYs. This study directly addresses this evidence gap.

Assessment of health status in children differs from adults and requires a different conceptual approach due to rapid rates of development, dependency on parents/caregivers and differences in disease epidemiology [19]. Utility-based HRQOL in children therefore needs to be measured using an instrument specifically designed for children. The CHU9D is a recently developed generic HRQOL measure designed to produce utility information. Originally tested for 7-11 year olds [20,21], it has more recently demonstrated good construct validity in adolescents aged 11-17 years [22]. Although there is emerging evidence regarding the psychometric properties of the CHU9D instrument $[22,23]$, more evidence is required with respect to its validity for use in different age groups and country settings. Different terms are used in the literature to describe validity, and in this context, discriminant validity refers to the degree with which the instrument discriminates between groups with known differences, and convergent validity refers to the degree to which two theoretically related measures of construct are actually related. Both are subtypes of construct validity [24].

This paper explored the relationship between weight status and utility-based HRQOL (measured on a $0-1$ scale reflecting full health and death) in children aged 5-6 years. Also it examined the construct validity of the CHU9D instrument by reporting specifically on the discriminant and convergent validity. To facilitate this assessment, the CHU9D was directly compared to the PedsQL instrument [25], a widely used, validated generic HRQOL measure in children.

\section{Methods}

The WAVES study is a UK-based cluster-randomised controlled trial assessing clinical and cost-effectiveness of an obesity prevention intervention targeting children, funded by the UK National Institute for Health Research (ISRCTN97000586; Date of registration: 19/5/2010) from 2010 to 2015. Fifty-four schools (recruited from a random sample of 200) participated in the study. The study had full ethics approval and was conducted in accordance with the World Medical Association's Declaration of Helsinki (National Research Ethics Service Committee, West Midlands, The Black Country No. 10/H1202/69). The random sample was weighted to achieve sufficient representation (to enable sub group analysis) from the two most prevalent ethnic minority groups in the West Midlands, UK: South Asian (Bangladeshi, Indian and Pakistani) and Black (African and Caribbean). All children in school year 1 (aged 5-6) from participating schools were invited to take part. Written parental consent was obtained for each study participant through a signed consent form and verbal assent from the children at the point of measurement. Parental consent was obtained for 1470 children (60\% of those eligible), and 1401 children $(95 \%$ of those consented $/ 57 \%$ of those eligible) were available for baseline measurements. For practical reasons the schools were split into two groups, half the schools had baseline measurements taken in 2011 and the other half in 2012. Data on participants' date of birth, sex and postcode were obtained from school records. Ethnicity data were collected through a parent completed questionnaire, or school records when this was not available. Small area deprivation was used as a proxy for socioeconomic status. Deprivation was assessed using the index of multiple deprivation (IMD) [26]. The IMD score for the residential area of each child was identified based on their postcode using an online facility [27]. These scores were then allocated to the appropriate IMD quintile; those in the first quintile, living in an area classified by the IMD as one of the $20 \%$ most deprived in England and those in the $5^{\text {th }}$ in an area classified as one of the $20 \%$ least deprived.

\section{Measurement of weight status}

For all participants, height and weight measures were taken at school by trained researchers using standardised instruments and procedures. Height was measured to the nearest $0.1 \mathrm{~cm}$ using a Leicester height measure. Weight was measured in light clothing without shoes to the nearest $0.1 \mathrm{~kg}$ using a Tanita SC-331 S body composition analyser. BMI was calculated by dividing weight (in kilograms) by height (in metres) squared $(\mathrm{kg} / \mathrm{m} 2)$ and used to categorise the children into underweight, healthy weight, overweight and obese groups. The $2^{\text {nd }}, 85^{\text {th }}$ and $95^{\text {th }}$ centiles of the UK 1990 Growth reference charts for BMI [28] were used to define the four weight categories, in line with standard UK definitions [29]. 


\section{HRQOL measures}

As the focus of this study was to explore the association between weight status and HRQOL when measured in utility terms, two instruments were selected for the measurement of HRQOL. Both are generic instruments and thus are designed to measure a wider notion of HRQOL and are not specific to any one disease or condition. The CHU9D is a preference-based utility instrument designed exclusively for use in children and previous research has shown this instrument is the most appropriate choice in this age group [30]. As a utility-based instrument, it is designed to produce a HRQOL score that is preference-based and set between the values of 0 (death) and 1 (full health), however like many preference-based utility instruments, it does produce scores that are deemed to be 'worse than death' and therefore have values of less than 0 . The PedsQL was chosen as a 'gold standard' comparator as this is a widely used HRQOL instrument validated for use in this age group and was the instrument of choice for the WAVES trial from which the data was generated. Although this instrument is non-utility based would be expected to generate HRQOL values which move in the same direction as the CHU9D utility values.

\section{CHU9D}

The CHU9D instrument contains 9 dimensions: school work/homework; tired; sleep; worried; sad; annoyed; daily routine; ability to join in activities; and pain, and every dimension contains 5 levels indicating the severity of the dimension. Each of the possible 1,953,125 unique health states are assigned a health utility value ranging from 0.33 to 1 based on an algorithm that reflects the preference weight attached to each dimension [31] .

\section{PedsQL}

The PedsQL is a 23-item instrument including four domains: physical (8 items), emotional (5 items), social (5 items), and school (5 items) functioning [25, 32]. For this study we used the child self-report PedsQL version designed for use in 5-7 year olds. Emerging from the instrument is a score (transformed on to a $0-100$ scale) for each type of functioning, with higher scores indicating better quality of life. Each item has three response options: not at all; sometimes; a lot; which in the scoring process are assigned values of $100 ; 50$; 0 , respectively. Provided data are available for at least half of the relevant items, the mean score for each of the four domains is then calculated by summing the values for the relevant items and dividing by the number of items answered. This is repeated including all items for the total score. The PedsQL instrument has good reliability and validity in both sick and healthy populations [32-35].

Both the CHU9D and the PedsQL were administered at the same time point by researchers on a one-to-one basis. The items and possible responses were read out and to help the children understand how to answer, for the PedsQL, a visual prompt (of a face ranging from smiley to sad associated with each response option) was provided as recommended by the developers of the instrument for administration to young children.

\section{Statistical analysis}

In the absence of a gold standard for the measurement of utility-based HRQOL in young children, and with no prior knowledge of how weight status affects utility-based HRQOL in children, to measure the construct validity of the CHU9D, we looked at the relationship between CHU9D and PedsQL in relation to weight status. This method allowed us to explore two subtypes of construct validity: discriminant and convergent validity. We explored discriminant validity by determining if the CHU9D instrument was able to discriminate between children within different weight groups, and the convergent validity by assessing how the CHU9D correlated with the PedsQL measure.

To explore the relationship between HRQOL and sample characteristics we report mean (and SD) CHU9D and PedsQL scores by weight status category, gender, ethnic group and deprivation quintile. Differences in HRQOL scores between groups were assessed using either the Kruskal-Wallis test, or the non-parametric test for trend. To examine the construct validity of the CHU9D, we split the sample according to the median PedsQL total score and examined separately the mean CHU9D utility value for children who scored on or above this median score, and those who scored below it. This difference was then compared using the one-way ANOVA test. Next, we looked at the distribution of response to each of the CHU9D dimensions by weight status category to assess if there were any significant differences in response. We hypothesised that children in the overweight and obese category would report more problems in each dimension compared to children in the healthy and underweight category. We assessed the significance of differences in response using the chi-squared test. To determine how well the PedsQL scores correspond with the CHU9D dimensions we estimated the mean PedsQL total score for each level of CHU9D response with the expectation that with increasing severity on each CHU9D dimension, the mean PedsQL total score would be lower. A scatter plot (along with fitted regression line and $95 \%$ CIs) for the CHU9D utility values and the total PedsQL scores was used to visualise the correlation between the instruments, and the correlation coefficient was calculated using the Spearman's rho statistic. To explore the correlation further we looked at the relationship between theoretically similar dimensions within both instruments. Our prior expectation was that the following dimensions would be correlated: 


\begin{tabular}{ll}
\hline PedsQL Instrument & CHU9D instrument \\
Physical functioning & $\begin{array}{l}\text { Tired/Able to join in activities/ } \\
\text { Daily routine/Pain/Sleep }\end{array}$ \\
Emotional functioning & Sad/Annoyed/Worried \\
Social functioning & Able to join in activities \\
School functioning & School work/home work \\
\hline
\end{tabular}

Finally, to compare the CHU9D utility values between the weight groups we used a linear mixed regression model (with random effect for school), adjusted for potential confounders (age, gender, ethnicity and deprivation quintile). All analyses were undertaken in 2014, using Stata version 13.

\section{Results}

Full data (including PedsQL total score, CHU9D utility value, and weight status group) were available for 1344 children and are presented in Table 1 . The proportion of children in the study sample who were either obese or overweight $(21.7 \%)$ is similar to the most comparable national data available [36] in which $22.6 \%$ of children measured in their Reception Year during the 2011/12 school year were classified as overweight or obese.

\section{Discriminant validity}

Using the known-groups method, the CHU9D (but not the PedsQL) differentiated HRQOL in children of different ethnic origin $(p=0.028)$ with White British children having the highest mean utility score (Table 2). There was a statistically significant trend of decreasing HRQOL by increasing level of deprivation which was identified by both instruments $(P<0.05)$. When children were categorised into two groups according to their weight status, neither instrument differentiated between the two groups.

To explore the discriminant validity of the CHU9D instrument, the mean and standard deviations for the CHU9D utility values were estimated for children who had a score either above, or below, the median PedsQL total score (71.73) for the sample. The mean utility scores were 0.87 (SD 0.109) and 0.76 (SD 0.143) respectively $(p<0.001)$.

Table 3 shows the distribution of the CHU9D dimensions by weight status category. Overall, the majority of children had no or few problems for all dimensions, irrespective of weight status. There were no underlying differences in the distribution of response to any of the CHU9D dimensions between children in the different weight categories.

Table 4 shows how the mean PedsQL scores corresponded with the options for each of the CHU9D dimensions. The mean PedsQL total scores decrease
Table 1 Sample Characteristics

\begin{tabular}{|c|c|}
\hline Characteristics & \\
\hline \multicolumn{2}{|l|}{ Gender: $\mathrm{n}(\%)(n=1344)$} \\
\hline Male & $695(51.7)$ \\
\hline Female & $649(48.3)$ \\
\hline Age: mean (SD) $(n=1344)$ & $6.3(0.31)$ \\
\hline \multicolumn{2}{|l|}{ Ethnic origin: $\mathrm{n}(\%)(n=1328)$} \\
\hline White British & $603(45.4)$ \\
\hline South Asian & $403(30.3)$ \\
\hline African Caribbean & $107(8.1)$ \\
\hline Other & $215(16.2)$ \\
\hline \multicolumn{2}{|l|}{ Deprivation quintile: $\mathrm{n}(\%)(n=1324)$} \\
\hline 1 Most deprived & $738(55.8)$ \\
\hline 2 & $239(18.1)$ \\
\hline 3 & $146(11.0)$ \\
\hline 4 & $113(8.5)$ \\
\hline 5 Least deprived & $88(6.6)$ \\
\hline \multicolumn{2}{|l|}{ Weight: $\mathrm{n}(\%)(n=1344)$} \\
\hline Underweight & $40(3.0)$ \\
\hline Healthy weight & $1012(75.3)$ \\
\hline Overweight & $116(8.6)$ \\
\hline Obese & $176(13.1)$ \\
\hline CHU9D mean score (SD) $(n=1344)$ & $0.825(0.14)$ \\
\hline \multicolumn{2}{|l|}{ PedsQL mean score (SD): } \\
\hline PedsQL Physical functioning $(n=1344)$ & $74.03(17.56)$ \\
\hline PedsQL Emotional functioning $(n=1344)$ & $72.32(22.74)$ \\
\hline PedsQL Social functioning $(n=1344)$ & $68.11(22.23)$ \\
\hline PedsQL School functioning $(n=1344)$ & $67.15(21.89)$ \\
\hline PedsQL Psychosocial functioning $(n=1344)$ & $68.93(18.13)$ \\
\hline PedsQL Total scale score $(n=1344)$ & $70.44(16.04)$ \\
\hline
\end{tabular}

linearly with increasing severity on each of the CHU9D dimensions.

\section{Convergent validity}

Figure 1 shows the relationship between the CHU9D utility values and the PedsQL total scores. Although there is a moderate association between the instruments with higher CHU9D utility values corresponding with higher PedsQL total scores, there are some anomalies. For example, one child reported a CHU9D utility of 0.32, yet had a PedsQL total score of 76.09, and another child reported a CHU9D utility score of 0.9 , yet had a PedsQL total score of 13.04.

Overall, the correlation between the CHU9D utility values and PedsQL total scores showed a statistically significant moderate, positive correlation ( $\mathrm{rs}=.4696, p=$ $<0.001)$. The content and coverage of the two instruments were further assessed by examining the correlation 
Table 2 Mean CHU9D and PedsQL scores grouped by respondent characteristics

\begin{tabular}{|c|c|c|c|}
\hline & Number & $\begin{array}{l}\text { Mean CHU9D } \\
\text { Utility (SD) }\end{array}$ & $\begin{array}{l}\text { PEDSQL total } \\
\text { score (SD) }\end{array}$ \\
\hline \multicolumn{4}{|l|}{ Gender } \\
\hline Male & 695 & $0.826(0.14)$ & $71.10(16.81)$ \\
\hline Female & 649 & $0.824(0.13)$ & $69.72(15.17)$ \\
\hline$p^{\mathrm{a}}$ & & 0.38 & 0.05 \\
\hline \multicolumn{4}{|l|}{ Ethnic Origin: } \\
\hline White British & 603 & $0.836(0.13)$ & $71.41(16.07)$ \\
\hline Asian & 403 & $0.809(0.15)$ & $69.19(15.66)$ \\
\hline African Carribean & 107 & $0.818(0.15)$ & $69.18(18.35)$ \\
\hline Other & 215 & $0.822(0.12)$ & $70.63(15.27)$ \\
\hline$p^{\mathrm{a}}$ & & 0.02 & 0.09 \\
\hline \multicolumn{4}{|l|}{ Weight status groups: } \\
\hline Underweight & 40 & $0.851(0.13)$ & $72.52(17.51)$ \\
\hline Normal weight & 1012 & $0.825(0.14)$ & $70.81(15.57)$ \\
\hline Overweight & 116 & $0.811(0.14)$ & $67.97(16.12)$ \\
\hline Obese & 176 & $0.827(0.13)$ & $69.44(18.13)$ \\
\hline$p^{\mathrm{b}}$ & & 0.33 & 0.28 \\
\hline \multicolumn{4}{|l|}{ Weight status groups: } \\
\hline $\begin{array}{l}\text { Underweight/ } \\
\text { Healthy weight }\end{array}$ & 1052 & $0.83(0.14)$ & $70.87(15.64)$ \\
\hline Overweight/obese & 292 & $0.82(0.13)$ & $68.86(17.35)$ \\
\hline$p^{\mathrm{b}}$ & & 0.30 & 0.18 \\
\hline \multicolumn{4}{|l|}{ Deprivation quintiles: } \\
\hline 1 Most deprived & 738 & $0.81(0.14)$ & $69.17(16.28)$ \\
\hline 2 & 239 & $0.81(0.14)$ & $71.14(16.10)$ \\
\hline 3 & 146 & $0.84(0.13)$ & $73.04(15.19)$ \\
\hline 4 & 113 & $0.82(0.13)$ & 71.48 (15.98) \\
\hline 5 Least deprived & 88 & $0.86(0.11)$ & $72.97(14.45)$ \\
\hline$p^{b}$ & & $<0.001$ & 0.002 \\
\hline
\end{tabular}

${ }^{\mathrm{a}}$ Kruskal-Wallis test; ${ }^{\mathrm{b}}$ non-parametric test for trend

between individual CHU9D dimensions and the theoretically similar PedsQL domains (Table 5).

Using conventional cut-off values for Spearman's $\rho$, we found that each CHU9D dimension was either weakly, or very weakly correlated with each of the predetermined PedsQL domain functioning scores. As the CHU9D dimensions are coded with 1 as highest level and 5 as lowest level, the signs on the coefficients were consistently negative.

Table 6 shows the results of the linear mixed regression model (with random effect for school) which compared the CHU9D utility score between the two weight status groups, adjusted for potential confounders (age, gender, ethnicity and deprivation quintile). Children who are overweight or obese have a lower CHU9D utility value (i.e. poorer HRQOL) but this association is not statistically significant. Children from a non-White British background have lower mean CHU9D utility values and this association approaches significance $(p=$ 0.07) for the South Asian population. Also, children from the least deprived areas have significantly higher CHU9D utility values relative to children from the most deprived areas.

\section{Discussion}

Weight management interventions increasingly target preadolescent children and this has implications for the methods of outcome measurement within economic evaluation as few instruments exist that are designed to elicit utilities in this age group. This paper contributes evidence on the use of the newly developed utility-based CHU9D instrument, within an ethnically and socioeconomically diverse UK population of young children.

\section{Relationship between CHU9D and weight status}

The results indicate that there is no statistically significant relationship between the CHU9D utility values and weight status in children aged 5-6 years. Adjusted for potential confounding factors, compared to the healthy/ underweight group, children who were overweight/obese reported lower CHU9D utility values, but this effect was not statistically significant. A similar result was found using the PedsQL. When focusing on the CHU9D dimensions, there were no statistically significant differences in scores by child weight status group for any of the dimensions.

Four previous studies that have measured utility-based HRQOL in children [18, 37-39] have shown similar findings. In a US-based study, Belfort et al. (2011) used the Health Utilities Index-2 (HUI-2) instrument to measure utility-based HRQOL in children and adolescents aged 5-18 years, and found that utility scores were, on average, 0.04 lower in overweight/obese participants compared with healthy weight [37]. Boyle et al. (2010) used the EQ-5D-Y to investigate the effect of weight on the HRQOL in a UK-based population aged 11-15 years and found children who were overweight or obese had a significantly lower HRQOL than children of healthy weight [38]. A recently published paper explored the relationship between BMI and HRQOL using CHU9D in two cohorts of Australian children, aged 912 years and 14-16 years. They found mean CHU9D utility values to be lower in children who were overweight or obese (compared to 'healthy' weight children), but this effect was only significant in the younger age group [39]. Despite these reports of a negative relationship between HRQOL and being overweight in children, the evidence is mixed in terms of whether this effect reaches statistical significance. Within a UK-based pilot study that was linked to this study, the same direction of 
Table 3 Distribution of response to CHU9D dimensions by weight status category

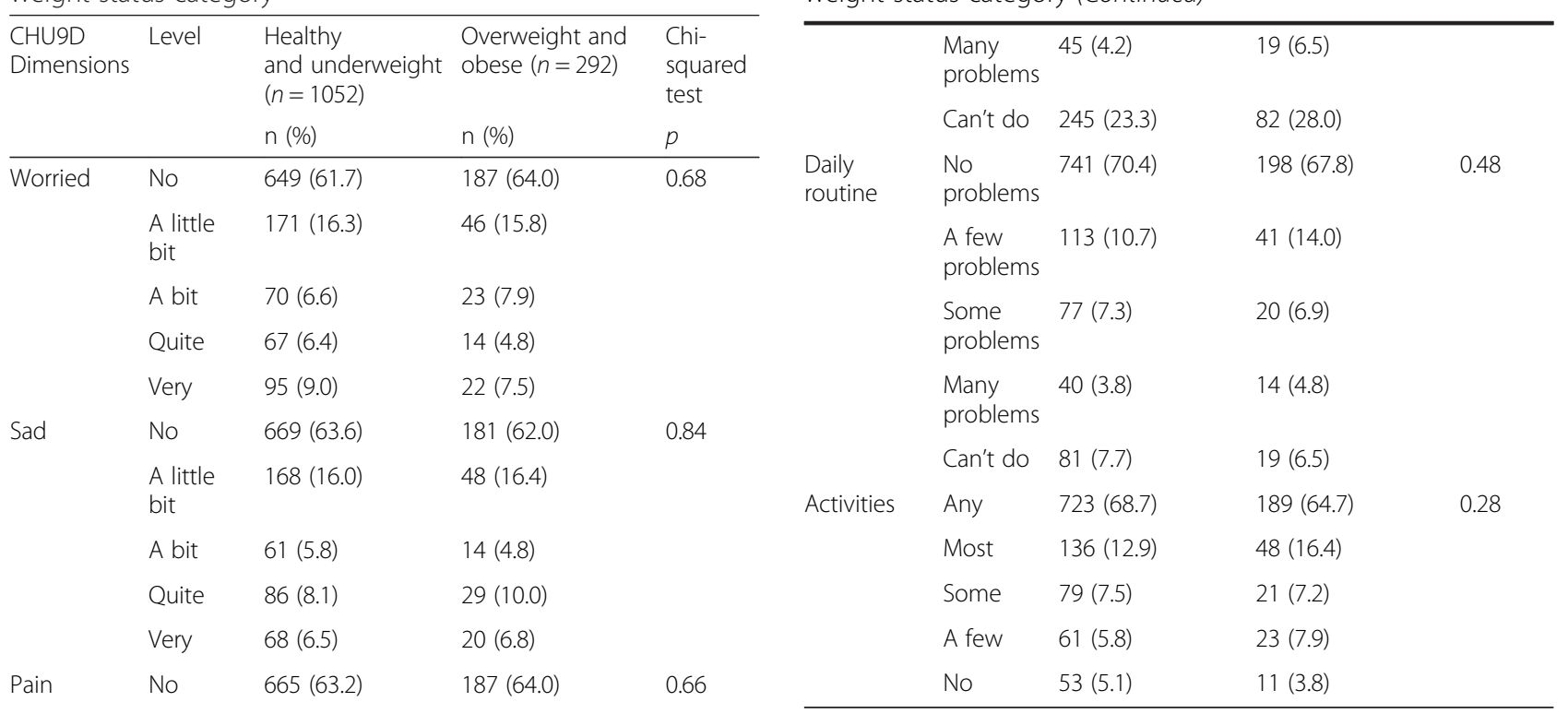

Table 3 Distribution of response to CHU9D dimensions by weight status category (Continued)
A little $\quad 191(18.2) \quad 51(17.5)$

bit

A bit $\quad 56(5.3) \quad 10(3.4)$

Quite $\quad 47(4.5) \quad 16(5.5)$

Very $\quad 93(8.8) \quad 28(9.6)$

Tired $\quad$ No $\quad 492(46.8) \quad 141(48.3)$

A little $183(17.4) \quad 61(20.9)$

bit

A bit $\quad 93(8.8) \quad 18(6.1)$

Quite $\quad 69(6.6) \quad 16(5.5)$

Very $215(20.4) \quad 56(19.2)$

Annoyed No $\quad 718(68.2) \quad 196(67$.

A little $\quad 117(11.1) \quad 28(9.6)$

bit

A bit $\quad 55(5.2) \quad 19(6.5)$

Quite $\quad 40(3.8) \quad 21(7.2)$

Very $\quad 122(11.6) \quad 28(9.6)$

School/ No $\quad 622(59.1) \quad 186(63.7)$

home work problems

A few $185(17.6) \quad 45(15.4)$
problems

Some $\quad 94(9.0) \quad 24(8.2)$

problems

Many $\quad 49(4.6) \quad 17(5.8)$

problems

Can't do $102(9.7) \quad 20(6.9)$

A few $140(13.3) \quad 38$ (13.0)

problems

Some $\quad 73(7.0) \quad 18(6.1)$

problems effect was found, but there was no statistical difference between utility values and weight status groups in children aged 5-6 years [18]. Three reasons were offered to help explain this result. The first related to the small pilot sample $(n=160)$, that may not have been large enough to assess subgroup differences. The sample size within this study population is substantially higher, and a similar result was found. The second reason suggested that the CHU9D is not sensitive enough to detect a difference in utility-based HRQOL between overweight and non-overweight children. In this study, the PedsQL total scores are available for comparison, and although the PedsQL shows a negative relationship between weight and HRQOL, again this does not reach statistical significance. Thirdly it was suggested that within this age group, the co-morbidities attached to obesity do not substantially affect HRQOL when measured on a $0-1$ utility scale, and it is only once these children approach adolescence that the effects of being overweight have a negative impact on utility values. This might help explain the results within this study.

\section{Psychometric properties of CHU9D}

This study has also contributed evidence on the construct validity of the CHU9D and the results support the convergent and the discriminant validity of the instrument. The most significant, consistent finding within the study population was that HRQOL when measured using both the CHU9D and the PedsQL, was lower within children from the most deprived areas, compared to children from the least deprived areas. This demonstrates that both instruments are discriminating between these groups of children with known differences. Also 
Table 4 Mean PedsQL score by each level of CHU9D dimension

\begin{tabular}{|c|c|c|c|c|}
\hline $\begin{array}{l}\text { CHU9D } \\
\text { Dimensions }\end{array}$ & Level & $n$ & $\begin{array}{l}\text { Mean PedsQL score } \\
\text { (SD) }\end{array}$ & $p^{a}$ \\
\hline \multirow[t]{5}{*}{ Worried } & No & 836 & $73.2(15.05)$ & \\
\hline & A little bit & 217 & $68.0(16.14)$ & \\
\hline & A bit & 93 & $68.6(15.70)$ & \\
\hline & Quite & 81 & $65.6(14.89)$ & \\
\hline & Very & 117 & $59.4(17.53)$ & $<0.001$ \\
\hline \multirow[t]{5}{*}{ Sad } & No & 850 & $72.9(15.10)$ & $<0.001$ \\
\hline & A little bit & 216 & $68.0(15.95)$ & \\
\hline & A bit & 75 & 66.6 (15.69) & \\
\hline & Quite & 115 & $65.8(16.37)$ & \\
\hline & Very & 88 & $60.8(18.66)$ & \\
\hline \multirow[t]{5}{*}{ Pain } & No & 852 & 72.7 (15.65) & $<0.001$ \\
\hline & A little bit & 242 & $69.4(14.81)$ & \\
\hline & A bit & 66 & $69.5(12.63)$ & \\
\hline & Quite & 63 & $63.5(16.33)$ & \\
\hline & Very & 121 & $60.0(17.39)$ & \\
\hline \multirow[t]{5}{*}{ Tired } & No & 633 & $75.2(15.17)$ & $<0.001$ \\
\hline & A little bit & 244 & $69.0(13.84)$ & \\
\hline & A bit & 111 & $67.6(16.60)$ & \\
\hline & Quite & 85 & $67.5(16.40)$ & \\
\hline & Very & 271 & 62.5 (15.74) & \\
\hline \multirow[t]{5}{*}{ Annoyed } & No & 914 & $73.1(15.43)$ & \\
\hline & A little bit & 145 & $66.5(15.10)$ & \\
\hline & A bit & 74 & $65.0(15.71)$ & \\
\hline & Quite & 61 & $65.2(16.41)$ & \\
\hline & Very & 150 & $62.3(16.11)$ & $<0.001$ \\
\hline \multirow{5}{*}{$\begin{array}{l}\text { School/home } \\
\text { work }\end{array}$} & No problems & 808 & $74.2(14.98)$ & $<0.001$ \\
\hline & $\begin{array}{l}\text { A few } \\
\text { problems }\end{array}$ & 230 & $67.7(14.23)$ & \\
\hline & $\begin{array}{l}\text { Some } \\
\text { problems }\end{array}$ & 118 & $63.8(16.75)$ & \\
\hline & $\begin{array}{l}\text { Many } \\
\text { problems }\end{array}$ & 66 & $62.0(16.33)$ & \\
\hline & Can't do & 122 & $60.9(16.67)$ & \\
\hline \multirow[t]{5}{*}{ Sleep } & No problems & 684 & 74.8 (15.78) & $<0.001$ \\
\hline & $\begin{array}{l}\text { A few } \\
\text { problems }\end{array}$ & 178 & $69.9(11.91)$ & \\
\hline & $\begin{array}{l}\text { Some } \\
\text { problems }\end{array}$ & 91 & $64.0(13.81)$ & \\
\hline & $\begin{array}{l}\text { Many } \\
\text { problems }\end{array}$ & 64 & $66.2(14.21)$ & \\
\hline & Can't do & 327 & $63.9(6.47)$ & \\
\hline \multirow[t]{3}{*}{ Daily routine } & No problems & 939 & 73.7 (14.92) & $<0.001$ \\
\hline & $\begin{array}{l}\text { A few } \\
\text { problems }\end{array}$ & 154 & 65.9 (15.19) & \\
\hline & $\begin{array}{l}\text { Some } \\
\text { problems }\end{array}$ & 97 & $65.2(15.63)$ & \\
\hline
\end{tabular}

Table 4 Mean PedsQL score by each level of CHU9D dimension (Continued)

\begin{tabular}{lllll}
\hline & $\begin{array}{l}\text { Many } \\
\text { problems }\end{array}$ & 54 & $59.3(15.57)$ & \\
Can't do & 100 & $56.8(15.57)$ & $<0.001$ \\
Activities & Any & 912 & $72.5(15.68)$ & \\
& Most & 184 & $69.0(16.28)$ & \\
& Some & 100 & $67.0(13.76)$ & \\
& A few & 84 & $64.1(15.62)$ & \\
& No & 64 & $58.0(15.68)$ &
\end{tabular}

with respect to discriminant validity, the results showed that the mean CHU9D values were significantly higher for all children with a PedsQL total score greater than or equal to the sample median total PedsQL score, compared to children with a PedsQL total score less than the sample median. Furthermore, PedsQL total scores corresponded well with the individual CHU9D dimensions, with a lower mean PedsQL total score with increasing severity on each CHU9D dimension. Regarding the convergent validity, overall, there was a moderate, statistically significant positive correlation between the PedsQL total scores and the CHU9D utility values. However, despite this correlation between the overall scores of both instruments, we found only a weak, or very weak correlation between the dimensions of each instrument that were pre-determined as being theoretically similar. One possible explanation is that although the PedsQL total scores and the CHU9D utility values tap into a similar underlying construct (HRQOL), the individual dimensions of each instrument, while appearing quite similar, might actually be describing something that is quite specific and different. So at the dimension level the correlations are weak but when combined, the overall instrument scores become moderately correlated.

\section{Strengths and weaknesses of the study}

The data within this study was collected from the WAVES trial which was designed to include a diverse socioeconomic and multi-ethnic population. Parental consent for participation in the WAVES trial was obtained for $57 \%$ of eligible pupils which could lead to sample selection bias. However when the proportion consented out of those eligible was considered by several socio-demographic characteristics, although there was some variation, the differences were generally modest (sex (boys $=65 \%$, girls $=67 \%$ ), ethnicity (white $=75 \%$, South Asian $=61 \%$, Black African Caribbean $=64 \%$; deprivation (most deprived quintile $=65 \%$, least deprived quintile $=72 \%$ ).

As it is rare to have utility information available for children as young as 5 years and for this to be reported 


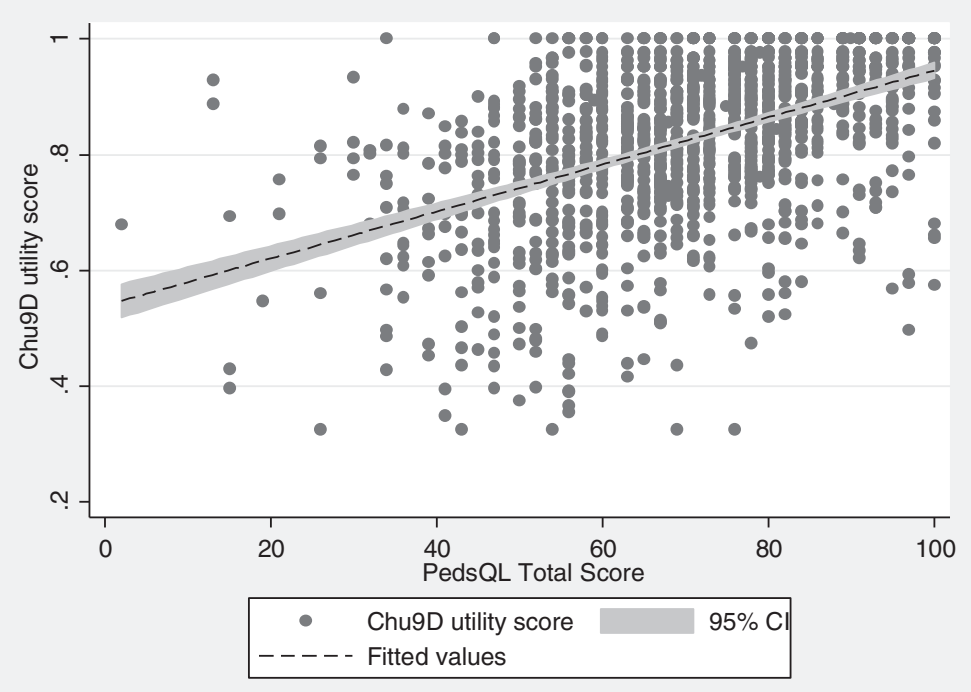

Fig. 1 Relationship between CHU9D utility scores and PedsQL total scores

for different weight groups, this study contributes this much needed evidence. There are some limitations to note however. First, this paper reports data from a trial and the available data therefore were restricted to what was collected as part of the trial. Ideally, it would have been interesting to assess the convergent validity of the CHU9D utility data with HRQOL data collected using an obesity-specific HRQOL instrument. This would have allowed us to determine if the weak association between weight and utility-based HRQOL in this age group was due to there being no underlying relationship there at all or a lack of sensitivity with detecting the negative effects of being overweight through use of a generic instrument. However, the PedsQL is widely viewed as a 'gold standard' generic measure of HRQOL, and has been validated and used in diverse populations. We suggest this as an

Table 5 Correlation between CHU9D dimensions and PedsQL domain functioning scores

\begin{tabular}{lll}
\hline CHU9D dimension & Correlation with PedsQL score & Spearman's $\rho^{a}$ \\
\hline Utility score & PedsQL total score & 0.47 \\
Worried & Emotional functioning & -0.18 \\
Sad & Emotional functioning & -0.18 \\
Pain & Physical functioning & -0.18 \\
Tired & Physical functioning & -0.26 \\
Annoyed & Emotional functioning & -0.22 \\
School work & School functioning & -0.21 \\
home work & & \\
Sleep & Physical functioning & -0.22 \\
Daily routine & Physical functioning & -0.28 \\
Able to join in activities & Social functioning & -0.13 \\
\hline
\end{tabular}

${ }^{\mathrm{a}}$ All were significant at 0.01 level area for future research. Second, all questions within the PedsQL and the CHU9D were read out to children by an interviewer and this might have had an influence on how children responded. This was a pragmatic decision as children in this age group have very different reading abilities making self-completion problematic but it could have influenced children's responses to the questions. Third, because of the very small number of children

Table 6 Results of linear mixed model to estimate variation in CHU9D between weight groups

\begin{tabular}{llll}
\hline Variables & $\begin{array}{l}\text { Mean } \\
\text { difference }\end{array}$ & $\begin{array}{l}95 \% \text { confidence } \\
\text { intervals }\end{array}$ & $\begin{array}{l}P_{-} \\
\text {value }\end{array}$ \\
\hline Mean value & 0.685 & $(0.529,0.841)$ & $<0.001$
\end{tabular}

Weight

Underweight/Healthy

weight

\begin{tabular}{llll}
\multicolumn{1}{l}{ Overweight/Obese } & -0.005 & $(-0.023,0.012)$ & 0.52 \\
Age (years) & 0.022 & $(-0.002,0.046)$ & 0.07 \\
Ethnic Group: & & & \\
$\quad$ White British & - & & \\
South Asian & -0.019 & $(-0.040,0.002)$ & 0.07 \\
African-Caribbean & -0.006 & $(-0.037,0.239)$ & 0.66 \\
Other & -0.005 & $(-0.028,0.185)$ & 0.66
\end{tabular}

Deprivation quintile:

1 Most deprived

\begin{tabular}{llll}
2 & 0.001 & $(-0.021,0.024)$ & 0.88 \\
3 & 0.019 & $(-0.007,0.047)$ & 0.15 \\
4 & -0.000 & $(-0.031,0.031)$ & 0.99 \\
Least deprived & 0.040 & $(0.003,0.077)$ & 0.03 \\
\hline
\end{tabular}


who were measuring 'underweight' in our sample (3\%) a decision was made to pull the 'underweight' and 'healthy' weight children into one weight category. There is no a priori reason to assume that the HRQOL of underweight and healthy weight children are similar but we could not explore this in a statistically robust fashion and the focus of this paper was on the effects of being overweight on HRQOL, not underweight. To enable a comprehensive analysis of the effects of being underweight would have required a purposive sampling approach to ensure adequate numbers of children in this category.

\section{Conclusion}

This paper contributes utility data from a large UKbased pediatric population alongside information on the psychometric properties of the instrument used to generate these data. Studies suggest that overweight is negatively associated with HRQOL in children but the extent of the association, how it varies across age groups, and how it translates to the $0-1$ utility scale is as yet underresearched. This paper offers support for the convergent and discriminant validity of the CHU9D, as a measure of utility-based HRQOL in children aged 5-6 years. It offers evidence that overweight is negatively associated with HRQOL in children in this young age group but that this association is weak. Utility values are frequently used within health economic studies conducted globally to derive QALYs to inform resource allocation decisions. Future studies need to determine how weight status is associated with HRQOL in utility terms, in different age cohorts, and across different country settings, to help inform the methods of economic evaluations alongside clinical trials of childhood obesity prevention and management.

\section{Abbreviations}

BMI: Body mass index; CHU9D: Child Health Utility 9D; HRQOL: health-related quality of life; HUI: Health Utilities Index; NICE: National Institute for Health and Care Excellence; PedsQL: Pediatric Quality of Life Inventory TM; QALYs: quality adjusted life years; WAVES: The West Midlands ActiVe lifestyle and healthy Eating in School children study.

\section{Competing interests}

All authors declare that they have no competing interests.

\section{Authors' contribution}

EF conceived the idea for the study, conducted part of the analysis and wrote the paper. MP, EL and PA collected the data for the study and edited the paper. $\mathrm{KH}$ carried out part of the analyses and edited the paper. All authors read and approved the final version of the manuscript.

\section{Acknowledgements}

This project was funded by the National Institute for Health Research (NIHR) Health Technology Assessment programme (project number 06/85/11). The views and opinion expressed therein are those of the authors and do not necessarily reflect those of the HTA programme, NIHR, NHS or the Department of Health.

\section{WAVES trial investigators}

Peymane Adab, Tim Barrett, KK Cheng, Amanda Daley, Jon Deeks, Joan Duda, Emma Frew, Paramjit Gill, Miranda Pallan, Jayne Parry - University of Birmingham; UIf Edland - Cambridge MRC Epidemiology Unit; Janet Cade University of Leeds; Raj Bhopal - University of Edinburgh.

\section{Trial collaborators}

Eleanor McGee - Birmingham East and North PCT; Sandra Passmore Birmingham Local Education Authority.

\section{Trial management group}

Emma Lancashire, Miranda Pallan, Peymane Adab - University of Birmingham

\section{Research Team}

Behnoush Ahranjani, Jo Clark, Tania Griffin, Kiya Kelleher, Emma Lancashire, Alastair Canaway, Karla Hemming.

\section{Steering committee}

Peymane Adab, John Bennett, Kelvin Jordan, Karla Hemming, Louise Longworth, Peter Whincup.

\section{Author details}

${ }^{1}$ Health Economics Unit, University of Birmingham, Birmingham B15 2TT, UK. ${ }^{2}$ Department of Public Health, Epidemiology and Biostatistics, School of Health and Populations Sciences, University of Birmingham, Birmingham B15 $2 T T$, UK.

Received: 5 May 2015 Accepted: 9 December 2015

Published online: 16 December 2015

\section{References}

1. Baker JL, Olsen LW, Sorensen TIA. Childhood body mass index and the risk of coronary heart disease in adulthood. N Engl J Med. 2007;357:2329-37.

2. Lobstein T, Baur L, Uauy R. Obesity in children and young people: a crisis in public health. Obes Rev. 2004:5(Suppl):4-85.

3. Singh AS, Mulder C, Twisk JWR, van Mechelen W, Chinapaw MJM. Tracking of childhood overweight into adulthood: a systematic review of the literature. Obes Rev. 2008:9:474-88.

4. European Commission/ Health \& Consumer Protection Directorate-General. Ten key facts about nutrition and obesity; 2014. http://ec.europa.eu/health/ archive/ph_determinants/life_style/nutrition/documents/10keyfacts_nut_ obe.pdf. Accessed January 2015.

5. McPherson K, Marsh T, Brown M. Tackling Obesities: Future Choices Modelling Future Treatment in Obesity and the Impact on Health. Governement Office for Science Foresight Report; 2007. http://news.bbc.co. uk/1/shared/bsp/hi/pdfs/22_11_07_modelling_fat.pdf. Accessed January 2015.

6. Waters E, De Silva-Sanigorski A, Hall BJ, Brown T, Campbell TJ, Gao Y et al. Interventions for preventing obesity in children (Review). Cochrane Database Syst Rev. 2011;7(12):CD001871. doi:10.1002/14651858.CD001871. pub3.

7. Doll HA, Petersen SEK, Stewart-Brown SL. Obesity and physical and emotional well-being: associations between body mass index, chronic illness, and the physical and mental components of the SF-36 questionnaire. Obes Res. 2000;8:160-70.

8. Fine JT, Colditz GA, Coakley EH, Moseley G, Willet WC, Kawachi I. A prospective study of weight change and health-related quality of life. JAMA. 1999;282:2136-42.

9. Han TS, Tijhuis MA, Lean ME, Seidell JC. Quality of life in relation to overweight and body fat distribution. Am J Public Health. 1998;88:1814-20.

10. Jia H, Lubetkin El. The impact of obesity on health related quality of life in the general adult US population. J Public Health. 2005;27:156-64.

11. Lean ME, Han TS, Seidell JC. Impairment of health and quality of life in people with large waist circumference. Lancet. 1998;351:853-6.

12. Griffiths LPT, Hill AJ. Self-esteem and quality of life in obese children and adolescents: A systematic review. Int J Pediatr Obes. 2010;5:282-304.

13. Swallen KC, Reither EN, Haas SA, Meier AM. Overweight, obesity, and healthrelated quality of life among adolescents: the National Longitudinal Study of Adolescent Health. BMC Public Health. 2012;12:997. 
14. Wallandar JL, Kerbawy S, Toomey S, Lowry R, Elliot MN, Escobar-Chaves SL, et al. Is obesity associated with reduced health-related quality of life in Latino, Black and White children in the community? Int J Obes. 2013;37:920-5.

15. National Institute for Health and Care Excellence (NICE). Guide to the methods of technology appraisal 2008. Available from: http://www.nice.org. uk/media/B52/A7/TAMethodsGuideUpdatedJune2008.pdf.

16. Neumann P. Greenberg: Is the United States ready for QALYs? Health Aff. 2009:28:1366-71.

17. Whitehead SJ, Ali S. Health outcomes in economic evaluation: the QALY and utilities. Br Med Bull. 2010;96:5-21.

18. Canaway A, Frew E. Is utility-based quality of life in children aged 6-7 years affected by Body Mass Index (BMI)? International Journal of Obesity. 2014; 38:1146. doi:10.1038/ijo.2013.219.

19. Ungar W. Economic evaluation in child health. Oxford: Oxford University Press; 2010.

20. Stevens KJ. Working with children to develop dimensions for a preferencebased, generic, pediatric health-related quality of life measure. Qual Health Res. 2010;20:340-51.

21. Stevens KJ. Assessing the performance of a new generic measure of health realted quality of life for children and refining it for use in health state valuation. Appl Health Econ Health Policy. 2011;9:157-69.

22. Ratcliffe J, Stevens K, Flynn T, Brazier J, Sawyer M. An assessment of the construct validity of the CHU9D in the Australian adolescent general population. Qual Life Res. 2012;21:717-25.

23. Stevens K, Ratcliffe J. Measuring and valuing health benefits for economic evaluation in adolescence: an assessment of the practicality and validity of the Child Health Utility 9D in the Australian adolescent population. Value Health. 2012;15:1092-9.

24. Cronbach $\amalg$, Meehl PE. Construct validity in pscyhological tests. Psychol Bull. 1955;52:281-302.

25. Varni JW, Seid M, Rode CA. The PedsQL measurement model for the pediatric quality of life inventory. Medical Care. 1999;37(2):126-139.

26. The UK Government Web Archive. Communities and Local Government, Indices of Deprivation 20017. The National Archives; 2010. http:// webarchive.nationalarchives.gov.uk/+/http:/www.communities.gov.uk/ communities/neighbourhoodrenewal/deprivation/deprivation07/. Accessed January 2015

27. Mimas National Services. University of Manchester. http://www.itservices. manchester.ac.uk/our-services/research/mimas/. Accessed January 2015.

28. Cole T, Freeman J, Preece M. Body mass index reference curves to the UK, 1990. Arch Dis Child. 1995:73:25.

29. National Obesity Observatory (NOO). A simple guide to classifying body mass index in children; 2011. Available from: http://www.noo.org.uk/ uploads/doc/vid_11601_A_simple_guide_to_classifying_BMI_in_children. pdf.

30. Canaway A, Frew E. Measuring preference based quality of life in children aged 6-7 years: A comparison of the performance of CHU-9D and EQ-5D-Y. The WAVES pilot study. Qual Life Res. 2014;22:173-82.

31. Stevens K. Valuation of the Child Health Utility 9D Index. Pharmacoeconomics. 2012;30:729-47.

32. Varni JW, Seid M, Rode CA. The Peds QL Measurement Model for the Pediatric Quality of Life Inventory. Med Care. 1999:37:126-39.

33. Varni JW, Seid M, Murtin PS. PedsQL 4.0: reliability and validity of the pediatric quality of life inventory version 4.0 generic core scales in healthy and patient populations. Med Care. 2001;39:800-12.

34. Varni JW, Burwinkle TM, Katz ER, Meeske K, Dickinson P. The PedsQL in pediatric cancer: reliability and validity of the pediatric quality of life inventory generic core scales, multidimensional fatigue scale, and cancer module. Cancer. 2002;94(7):2090-106.

35. Varni JW, Seid M, Knight TS, Burwinkle TM, Brown J, Szer IS. The PedsQL in pediatric rheumatology: reliability, validity, and responsiveness of the pediatric quality of life inventory generic core scales and rheumatology module. Arthritis Rheum. 2002;46:714-25.

36. Health and Social Care Information Centre. National Child Measurement Programme. http://www.hscic.gov.uk/ searchcatalogue? productid=10135\&q=title\%3a\%22national+child +measurement+programme\%22\&sort=Relevance\&size=10\&page=1\#top. 15 .

37. Belfort M, Zupancic J, Riera K, Runer J, Prosser L: Health state preferences associated with weight status in children and adolescents. BMC Pediatrics 2011, 11: doi:10.1186/1471-2431-11-12
38. Boyle S, Jones GL, Walters SJ. Physical activity, quality of life, weight status and diet in adolescents. Qual Life Res. 2010;19:943-54.

39. Chen G, Ratcliffe J, Olds T, Magarey A, Jones M, Leslie E: BMI, Health Behaviors, and Quality of Life in Children and Adolescents: A School-Based Study. Pediatrics 2014, 133: doi:10.1542/peds.2013-0622

\section{Submit your next manuscript to BioMed Central and we will help you at every step:}

- We accept pre-submission inquiries

- Our selector tool helps you to find the most relevant journal

- We provide round the clock customer support

- Convenient online submission

- Thorough peer review

- Inclusion in PubMed and all major indexing services

- Maximum visibility for your research

Submit your manuscript at www.biomedcentral.com/submit
C) BioMed Central 